\title{
Healthy Nutrition, Phytonutrients and Alzheimer's Disease
}

\author{
Martin Aldasoro, Anna Gil-Bisquert and Soraya L. Valles* \\ Department of Physiology, Faculty of Medicine and Odontology, University of Valencia, Spain
}

\section{Introduction}

In most areas of the world malnutrition in early life is directly or indirectly responsible of more deaths in children than other causes. Malnutrition is also a main concern in aged population. Nutritional deficiencies affect physical growth but also may produce irreversible mental and emotional changes. Many of these undesirable effects have been studied in animals [1]. Nutrition is of growing importance in degenerative diseases. Nilsson and coworkers have published that episodic memory performance i.e. the ability to recall events in time and place declines linearly with age. This decline in episodic memory began as early as at 20 years of age [2]. Thus, studies about nutrition influences in cognition should begin at early ages (20 years age or even less). Recent investigations in animals, on the physical and biochemical aging of the central nervous system, have provided helpful information to understand the effects of malnutrition. During maturation and growth, the amount of water in the brain gradually decreases, whereas the amount of cholesterol steadily increases $[3,4]$. Maturation consists of a rapid increase in cells, as indicated by the increased concentrations phosphorus of DNA. Whereas growth parallels myelination and is represented by increased amounts of cholesterol [4,5]. Inadequate nutrition in calories and proteins, coinciding with the period in life in which the brain is growing most rapidly, may result in a smaller (than in controls) brain at maturity. Also, in a brain which matures biochemically and functionally at a slower rate [5]. In the adult rat starvation does not result in significant changes in brain weight or in damages to neural tissue. However, malnutrition associated -oxidative stress and -inflammation occur in neurons and astrocytes in elderly brains which may damage differently neural tissues in a differential fashion [6]. A biological mechanism which can be linked to nutrition and have been associated with aging includes oxidative stress [7], inflammation [8], homocysteine [9], advanced glycation end products [10] and the provision of fatty acids [11]. These mechanisms have in common that they reflect the nature of the existing diet or eventually respond to changes in what we eat. Changes from normal cognition to dementia, which affect in specific brain structures, usually take place slowly over decades. It is in this time-dependent scenario where general brain shrinkage, reduced cerebral blood impaired, glucose tolerance, or related patterns may prove to be useful endpoints [12].

Dementia is not a disease but a group of symptoms which are common to different diseases, such as problems affecting, memory, and reasoning. Alzheimer's disease (AD) accounts for $50 \%$ to $70 \%$ of all dementia cases, and vascular dementia accounts for $10-15 \%$, whereas the rest includes about 50 other etiologies, so nutrition should be expected to have an impact in different ways $[13,14]$. The role of nutrition in AD's disease has not been studied and, phytonutrients in particular appear a very interesting subject for their health benefits [15]. Natural Polyphenols are present in many fruits and vegetables potential protection agonist neurodegenerative diseases has been suggested [15,16]. Among polyphenols, flavonoids represent the largest group. For instance the major phytoestrogen component of soy is genistein. We have found that which appears effective in preventing neuronal death caused by $\mathrm{A} \beta$ peptide in neurons in primary culture [17]. In fact the beneficial effects of phytoestrogens on central nervous system functions have received attention in the last decade, and estrogen therapy is one of the potential strategies for the prevention of dementia [18]. Genistein has immunosuppressive and antiinflammatory properties $[19,20]$. Data from our laboratory have shown that estradiol or genistein abolishes neuronal reactive oxygen species and attenuates $A \beta$-induced cell death in cortical neurons by preventing p38 activation and mitochondrial aggregation [17]. Genistein, at nutritionally relevant concentrations, can reproduce the protective effects of estradiol in neurons. In astrocytes, genistein is able to prevent $\mathrm{AD}$-associated inflammation by increasing PPAR $\gamma$ expression, thus suggesting potential anti-inflammatory properties against $\mathrm{AD}$ [21].

Other studies have shown that excessive alcohol uptake in rats can result in mitochondrial dysfunction in neurons and astrocytes leading to neurodegeneration $[22,23]$. Paradoxically, it is reported that moderate alcohol uptake associates with a lower risk of clinical stroke [24].

Researchers have shown a relationship between alcoholism and AD. Moderate alcohol intake produced benefits to AD patients compared to those who did not drink alcohol [25]. Grapes contain flavonoids such as resveratrol or its dimethylated analog pterostilbene, used as antifungal agents, anti-inflammatory drugs, antioxidants, and antiinfective agents [26]. Thus the beneficial effects of wine consumption on neurodegeneration are attributed to this type of molecules [27,28]. Resveratrol was reported to reduce $A \beta$ production in the HEK293cell line expressing wild type or Swedish-mutant APP695 and A $\beta$ damage mechanisms and the role of the proteosome in the clearance of $A \beta$ have been determined [29]. Therefore, a possible proteasome-dependent anti-amyloidogenic activity of natural polyphenols, such as resveratrol or pterostilbene appears an interesting (nutrition-related) next step in $\mathrm{AD}$ research.

Interestingly the prevalence of $\mathrm{AD}$ in Indian people 70 to 79 years old is 4.4 fold less than in a similar population of the United States [30]. The Indian diet is rich in spices such as chili, curry or curcumin. Curcumin in particular is a potent free radical scavenger, better than vitamin $\mathrm{E}$, which can provide effective protection against lipid peroxidation. Curcumin is also effective against the amyloid plaques in animal models. Thus, it appears be reasonable to speculate that curcumin could possibly prevent the onset of $\mathrm{AD}$ associated with oxidative stress [31].

South-American Indians knew the Stevia plant as "medicine for women" and use it in menopause an also to calm pain during menstruation. Probably its magnesium combats the cramps and its seven flavonoids (with estrogen-like effects) can ameliorate menopause symptoms [32]. Stevia has an additional property useful in alimentation, since it does not alter glucose blood levels but simultaneously satisfies appetite for something sweet. In animal experiments, stevia prevents atherosclerosis because increases superoxide dismutase enzyme

*Corresponding author: Soraya L. Valles, Department of Physiology, Faculty of Medicine and Odontology, University of Valencia, Spain, E-mail: Lilian.Valles@ uv.es

Received November 24, 2011; Accepted November 30, 2011; Published December 02, 2011

Citation: Aldasoro M, Gil-Bisquert A, Valles SL (2011) Healthy Nutrition Phytonutrients and Alzheimer's Disease. J Nutr Disorders Ther 1:e102. doi:10.4172/2161-0509.1000e102

Copyright: (c) 2011 Aldasoro M, et al. This is an open-access article distributed under the terms of the Creative Commons Attribution License, which permits unrestricted use, distribution, and reproduction in any medium, provided the original author and source are credited. 
Citation: Aldasoro M, Gil-Bisquert A, Valles SL (2011) Healthy Nutrition, Phytonutrients and Alzheimer's Disease. J Nutr Disorders Ther 1:e102. doi:10.4172/2161-0509.1000e102

Page 2 of 2

activists, thus removing oxidized LDL cholesterol and other harmful lipids from blood vessels wall [33]. The preventive effects of steviosides on the development of $\mathrm{AD}$ and its relationship with soy-based diet surely deserve further studies.

\section{References}

1. Cowley J J and Griesel R D (1963) THE DEVELOPMENT OF SECONDGENERATION LOW-PROTEIN RATS. J Genet Psycho 103: 233- 242.

2. Nilsson LG (2003) Memory function in normal aging. Acta Neurol Scand 179 7-13.

3. Arroyo P, Mandujano M (2000) Joaquin Cravioto (1922-1998). J Nutr 130: 2867-2869.

4. Eichenwald HF, Fry PC (1969) Nutrition and learning. Science. 163: 644-648.

5. Chan MM, Chan GM (2009) Nutritional therapy for burns in children and adults. Nutrition 25: 261-269.

6. Ramesh BN, Rao TS, Prakasam A, Sambamurti K, Rao KS (2010) Neuronutrition and Alzheimer's disease. J Alzheimers Dis 19: 1123-1139.

7. Malinin NL, West XZ, Byzova TV (2011) Oxidation as "the stress of life". Aging 3: $906-910$.

8. Gemma C, Bachstetter AD, Bickford PC (2010) Neuron-Microglia Dialogue and Hippocampal Neurogenesis in the Aged Brain. Aging Dis. 1: 232-244.

9. Zhuo JM, Wang H, Praticò D (2011) Is hyperhomocysteinemia an Alzheimer's disease $(A D)$ risk factor, an AD marker, or neither? Trends Pharmacol Sci 32 562-71.

10. Yaffe K, Lindquist K, Schwartz AV, Vitartas C, Vittinghoff E, et al. (2011) Advanced glycation end product level, diabetes, and accelerated cognitive aging. Neurology 77: 1351-1356.

11. Wattanapenpaiboon N, Wahlqvist MW (2003) Phytonutrient deficiency: the place of palm fruit. Asia Pac J Clin Nutr. 12: 363-368

12. Benton D (2010) Neurodevelopment and neurodegeneration: are there critical stages for nutritional intervention? Nutr Rev 68: S6-10.

13. Gralle M, Ferreira ST (2007) Structure and functions of the human amyloid precursor protein: the whole is more than the sum of its parts. Prog Neurobiol. 82: 11-32.

14. Clark TA, Lee HP, Rolston RK, Zhu X, Marlatt MW, et al. (2010) Oxidative Stress and its Implications for Future Treatments and Management of Alzheimer Disease. Int J Biomed Sci. 6: 225-227.

15. Ray B, Lahiri DK (2009) Neuroinflammation in Alzheimer's disease: differen molecular targets and potential therapeutic agents including curcumin. Curr Opin Pharmacol 9: 434-44.

16. Zhang H, Morgan B, Potter BJ, Ma L, Dellsperger KC, et al.(2010) Resveratro improves left ventricular diastolic relaxation in type 2 diabetes by inhibiting oxidative/nitrative stress: in vivo demonstration with magnetic resonance imaging. Am J Physiol Heart Circ Physiol 299: H985-H994.

17. Vallés SL, Borrás C, Gambini J, Furriol J, Ortega A, et al. (2008) Oestradiol or genistein rescues neurons from amyloid beta-induced cell death by inhibiting activation of p38. Aging Cell. 7: 112-118.

18. Craig MC, Murphy DG (2010) Estrogen therapy and Alzheimer's dementia. Ann N Y Acad Sci 1205: 245-253.

19. Genazzani AR, Plunchino N, Luisi E, Luise M (2007) Estrogen, cognition and female ageing. Hum. Reprod. 13: 175-187.

20. Ji G, Yang Q, Hao J, Guo L, Chen X, et al. (2011) Anti-inflammatory effect of genistein on non-alcoholic steatohepatitis rats induced by high fat diet and its potential mechanisms. Int Immunopharmacol 11: 762-768.

21. Valles SL, Dolz-Gaiton P, Gambini J, Borras C, Lloret A, Pallardo FV, et al. (2010) Estradiol or genistein prevent Alzheimer's disease-associated inflammation correlating with an increase PPAR gamma expression in cultured astrocytes. Brain Res 2: 138-144.

22. Blanco AM, Vallés SL, Pascual M, Guerri C (2005) Involvement of TLR4/type IL-1 receptor signaling in the induction of inflammatory mediators and cell death induced by ethanol in cultured astrocytes. J Immunol 175: 6893-6899.

23. Vallés SL, Blanco AM, Pascual M, Guerri C (2004) Chronic ethanol treatment enhances inflammatory mediators and cell death in the brain and in astrocytes. Brain Pathol. 14: 365-371.

24. Sacco RL, Elkind M, BodenAlbala B, Lin IF, Kargman DE, et al. (1999) The protective effect of moderate alcohol consumption on ischemic stroke. JAMA. 281: 53-60.

25. Ruitenberg A, vanSwieten JC, Witteman JC, Mehta KM, vanDuijn CM, et al. (2002) Alcohol consumption and risk of dementia: the Rotterdam study. Lancet 359: 281-286.

26. Ferrer P, Asensi M, Priego S, Benlloch M, Mena S, et al. (2007) Nitric oxide mediates natural polyphenol-induced $\mathrm{Bcl}-2$ down-regulation and activation of cell death in metastatic B16 melanoma. J Biol Chem 282: 2880-2890.

27. Jang JH, Surh YJ (2003) Protective effect of resveratrol on beta-amyloidinduced oxidative PC12 cell death. Free Radic Biol Med 34: 1100-1110.

28. Castellani RJ, Smith MA, Nunomura A, Harris PLR, Perry G (1999) Is increase redox-active iron in Alzheimer's disease failure of the copper binding protein ceruloplasmin? Free Radic Biol Med 26: 1508-1512.

29. Marambaud $P$, Zhao H, Davies $P$ (2005) Resveratrol promotes clearance of Alzheimer's disease amyloid-beta peptides. J Biol Chem 280: 37377-37382.

30. Ramesh BN, Rao TS, Prakasam A, Sambamurti K, Rao KS (2010) Neuronutrition and Alzheimer's Disease. J Alzheimers Dis 19: 1123-1139.

31. Ono K, Hasegawa K, Yoshiike Y, Takashima A, Yamada M, et al. (2002) Nordihydroguaiaretic acid potently breaks down pre-formed Alzheimer's betaamyloid fibrils in vitro. J Neurochem 81: 434-440.

32. Ghanta S, Banerjee A, Poddar A, Chattopadhyay S (2007) Oxidative DNA damage preventive activity and antioxidant potential of Stevia rebaudiana (Bertoni) Bertoni, a natural sweetener. J Agric Food Chem 26: 10962-10967.

33. Geeraert B, Crombé F, Hulsmans M, Benhabilès N, Geuns JM, et al.(2009) Natural sweetener stevioside inhibits atherosclerosis by increasing the antioxidant defense in obese, insulin-resistant mice. Stevia in Europe, KULeuven, Cap 6: 36-62. 